\title{
PELATIHAN PENGGUNAAN APLIKASI PENDETEKSI PALGIAT UNTUK DOSEN UNIVERSITAS LANCANG KUNING
}

\author{
Alexsander Yandra*1, Zamzami ${ }^{2}$, Bayu Febriadi ${ }^{3}$ \\ ${ }^{1}$ Program Studi Administrasi Negara, Fakultas Ilmu Administrasi, Universitas Lancang Kuning \\ ${ }^{2,3}$ Program Studi Sistem Informasi, Fakultas Ilmu Komputer, Universitas Lancang Kuning \\ Jalan Yos Sudarso KM. 08 Rumbai, Pekanbaru-Riau, (0761) 53108 -53236 \\ E-mail : alexsy@unilak.ac.id
}

\begin{abstract}
University Lancang Kuning which is one of the leading educational institutions in Riau province, also produces superior products that are outstanding students and ready to face the world of sprinting and outstanding lecturers, as stated in the yellowish university mission "Becoming a University of Excellence at National level based Malay culture ". Student research and lecturers refer to many previous studies, sometimes there are students or lecturers copy paste existing research without understanding that later what they copied from the research the person will make them as a plagiarist.
\end{abstract}

Keywords - Unilak, Plagiarism, Online, Offline

\begin{abstract}
Abstrak
Universitas lancang kuning yang merupakan salah satu lembaga pendidikan ternama di propinsi Riau, juga menghasilkan produk -produk yang unggul yaitu mahasiswa yang berprestasi dan siap menghadapi dunia perkejaan serta dosen yang berprestasi, yang tertuang dalam misi universitas lancang kuning "Menjadi Universitas Unggul di tingkat Nasional berlandaskan budaya Melayu". Penelitian mahasiswa maupun dosen banyak merujuk ke penelitian-penelitian yang ada sebelumnya, kadangkala ada mahasiswa atau dosen mengcopy paste penelitian yang ada tanpa mengerti bahawa nantinya apa yang mereka copy dari penelitian orang tersebut akan membuat mereka sebagai seorang plagiat.
\end{abstract}

Kata Kunci-Unilak, Plagiat, Online, Offline

\section{PENDAHULUAN}

Gajah mati meninggalkan gading, harimau mati meninggalkan belang dan manusia mati meninggalkan nama, baik itu nama baik maupun nama yang buruk. Supaya nantinya kita bias meninggalkan nama yang baik dari mulai dari sekarang banyak-banyaklah kita melakukan kebaikan dan menciptkan suatu karya untuk kebaikan, baik karya itu berupa bentuk benda, maupun hasil karya pikir seperti metode-metode, rumus-rumus, dan berupa hasil penelitian dan pengabdian.

Perkembangan teknologi yang tiap hari semakin membantu manusia dalam pekerjaannya, menjadikan manusia banyak menciptakan produk-produk yang dimanfaatkan oleh manusia dalam kehidupan sehari-hari sekaligus menunjang prodktifitas dalam tujuan mengefektifkan dan mengefisienkan setiap kegiatan manusia tersebut. Sebagaimana prinsip manusia modern yang segala sesuatu berorientasi pada kualitas hasil dari pekerjaan yang sedang dilaksanakan.

Universitas lancang kuning yang merupakan salah satu lembaga pendidikan ternama di propinsi Riau, juga menghasilkan produk - produk yang unggul yaitu mahasiswa yang berprestasi dan siap menghadapi dunia perkejaan serta dosen yang berprestasi, yang tertuang dalam misi universitas lancang kuning "Menjadi Universitas Unggul di tingkat Nasional berlandaskan budaya Melayu". Setiap mahasiswa untuk mandapatkan gelar kersarjanaan harus mengikuti perkuliahan dan pada akhir semester mereka harus membuat sebuah penelitian yang dituangkan dalam bentuk skripsi. Demikian juga setiap dosen yang terdaftar sebagai dosen di universitas lancang kuning wajib 
membuat sebuah penelitian dan pengabdian masyarakat sebagaimana kewajiban dosen untuk melaksanakan tri dharma pergurun tinggi.

Penelitian mahasiswa maupun dosen banyak merujuk ke penelitian-penelitian yang ada sebelumnya, kadangkala ada mahasiswa atau dosen mengcopy paste penelitian yang ada tanpa mengerti bahwa nantinya apa yang mereka copy dari penelitian orang tersebut akan membuat mereka sebagai seorang plagiat. Sangat resisten jika realitas ini terjadi secara jangka waktu yang panjang karena akan berdampak terhadap pelabelan akademik yang negative.

Untuk mengatasi permasalahan tersebut maka pelaksana pengabdian ingin mengadakan pelatihan penggunaan aplikasi pendeteksi plagiat agar nantinya dosen diprodi, LPPM, BPM dapat mengecek tingkat plagiarism dari penelitian mahasiswa ataupun dosen sebelum di usulkan atau di publish nantinya.

\section{METODE PELAKSANAAN}

Pelaksanaan kegiatan $\mathrm{I}_{\mathrm{B}} \mathrm{M}$ ini dilakukan di Fakultas Ilmu Komputer dengan metode ceramah, praktikum, tanya jawab dan evaluasi pencapaian target melalui kuisioner. Pelatihan dilakukan selama satu hari dimana peserta akan mendapatkan 1(satu) Compact Disk yang berisi aplikasi pendeteksi plagiat dan modul.

Metode ceramah diberikan saat pemberian materi dengan menggunakan slide persentasi dan handout materi. Metode evaluasi pencapaian target dilakukan pada awal (pre test) dan akhir kegiatan (post test). Hal ini untuk mengetahui tingkat pemahaman peserta dan menerima masukan untuk perbaikan pada kegiatan-kegiatan berikutnya. Secara rinci kegiatan pengabdian yang akan dilakukan sebagai berikut :

1. Kegiatan Sosialisasi penginstallan Aplikasi pendeteksi plagiat pada laptop atau masing-maing peserta,

2. Uji coba aplikasi tersebut secara offline tarhadapat penelitian dosen.

3. Uji coba aplikasi secara online tarhadapat penelitian dosen.

Sebelum melakukan installasi aplikasi pendeteksi plagiat sebaiknya mempersiapkan bahanbahan yang berkaitan dengan installasi seperti laptop, CD, dan Softwarenya.

\section{HASIL DAN PEMBAHASAN}

Dalam rangka meningkatkan kualitas tulisan-tulisan akademik dosen yang bebas dari plagiarism serta menjaga marwah Universitas Lancing Kuning dalam setiap publikasi ilmiah, maka diperlukan suatu kegiatan serta software anti plagiat yang bisa memfasilitasi para dosen di lingkungan Unilak agar memiliki tulisan yang bebas dari plagiarism Diharapkan hal tersebut juga bisa memperkuat posisi dan nilai tawar Unilak sebagai universitas kebanggaan masyarakat Riau. Oleh karena itu kami mengusulkan adanya pelatihan dan sosialisasi ke setiap dosen dan pengelola jurnal di lingkup Unilak. Sehubungan dengan hal tersebut maka dari beberapa aplikasi plagiat seperti checker X, Profesional dan Turnitin akhirnya pilihan ke turnitin dengan pertimbangan kualitas aplikasi dan standar penggunaan aplikasi di Indonesia. Berikut tim pelaksana pengabdian dengan tim Turnitin Bu Sastri dari IGROUP.

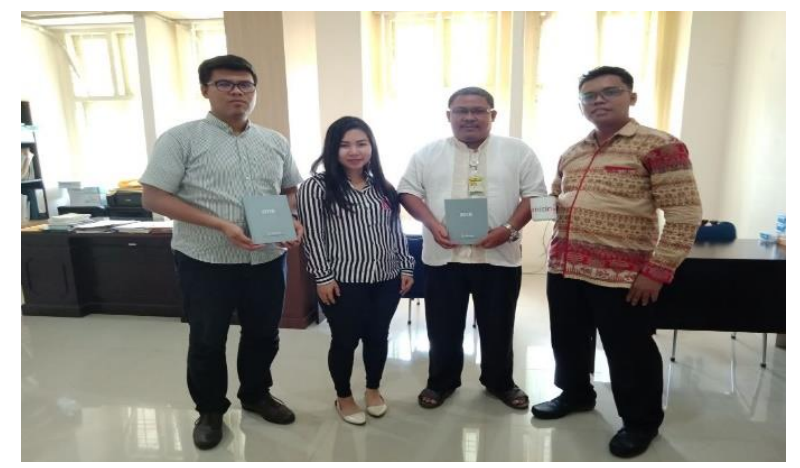

Gambar 1. Pelatihan Dan Kesepakatan Penggunaan Turnitin 
Turnitin merupakan sebuah software berbasis website yang memiliki fungsi untuk mengecek tingkat plagiasi yang terdapat pada tugas maupun skripsi mahasiswa, penelitian dan pengabdian dosen. Tujuan dari pemanfaatan software tersebut selain melihat tingkat plagiasi yaitu untuk memudahkan dosen dan reviewer dalam memberikan penilaian. Terlepas dari untuk menjaga integritas dan kejujuran mahasiswa dan dosen dalam mengerjakan tugas ilmiah, aplikasi ini dapat memudahkan dalam memberikan penilaian atas kualitas dari tugas yang dikerjakan, selain itu penilaian yang dilakukan akan lebih efektif dan efisien karena dapat diakses kapan saja dan dimana saja. Cara kerja dari software tersebut yaitu pada bagian tulisan yang terdeteksi mengcopy paste dari tulisan orang lain akan secara otomatis memiliki warna yang berbeda dari tulisan lainnya. "Kalimatkalimat yang mengandung unsur plagiat akan ditandai dengan warna berbeda-beda, serta dapat terdeteksi sumber website yang telah di copy paste oleh mahasiswa. Sebenarnya mengutip kalimat dari sumber website resmi sah-sah saja dilakukan, namun harus disertai dengan kutipan yang jelas dan sebagai penguat sumber tulisan yang telah dikutip sebagai bentuk apresiasi bagi penulis sebelumnya. Turnitin memang bisa di andalkan dalam menguji originalitas karya ilmiah sebagai dosen maupun pelajar. Salah satu fungsi dari turnitin ini yaitu bisa mengkoreki keaslian dokumen yang kita buat dan dalam program turnitin ini kita bisa mengetahui dari mana sumber artikel yang kita ambil dan akan tercantum pula sumber alamat websitenya.

Banyak sekali dari universitas yang sudah menggunakan turnitin karena sangat berguna yaitu untuk mengkoreksi sebuah karya tulis ilmiah dan sebagainya di harapkan prodi, LPPM dan BPM dapat mengoptimalkan aplikasi ini untuk mendukung Unilak unggul di tingkat nasional maupun internasional.

Pelatihan penggunaan aplikasi anti plagiat sudah dilakukan bagi pengelola Jurnal Dinamisia LPPM Universitas Lancang Kuning khusus untuk aplikasi Checker-X, secara direct setiap artikel yang submit seblum masuk editing dilakukan proses check dan ricek plagiat, hal ini untuk mengurangi kemungkinan adanya tuntutan dari pihak tertentu serta menjamin kualitas artikel yang akan nantinya di publish. Berikut penjelasan pelaksanaan kegiatan pelatihan penggunaan aplikasi anti plagiat pengelola jurnal,

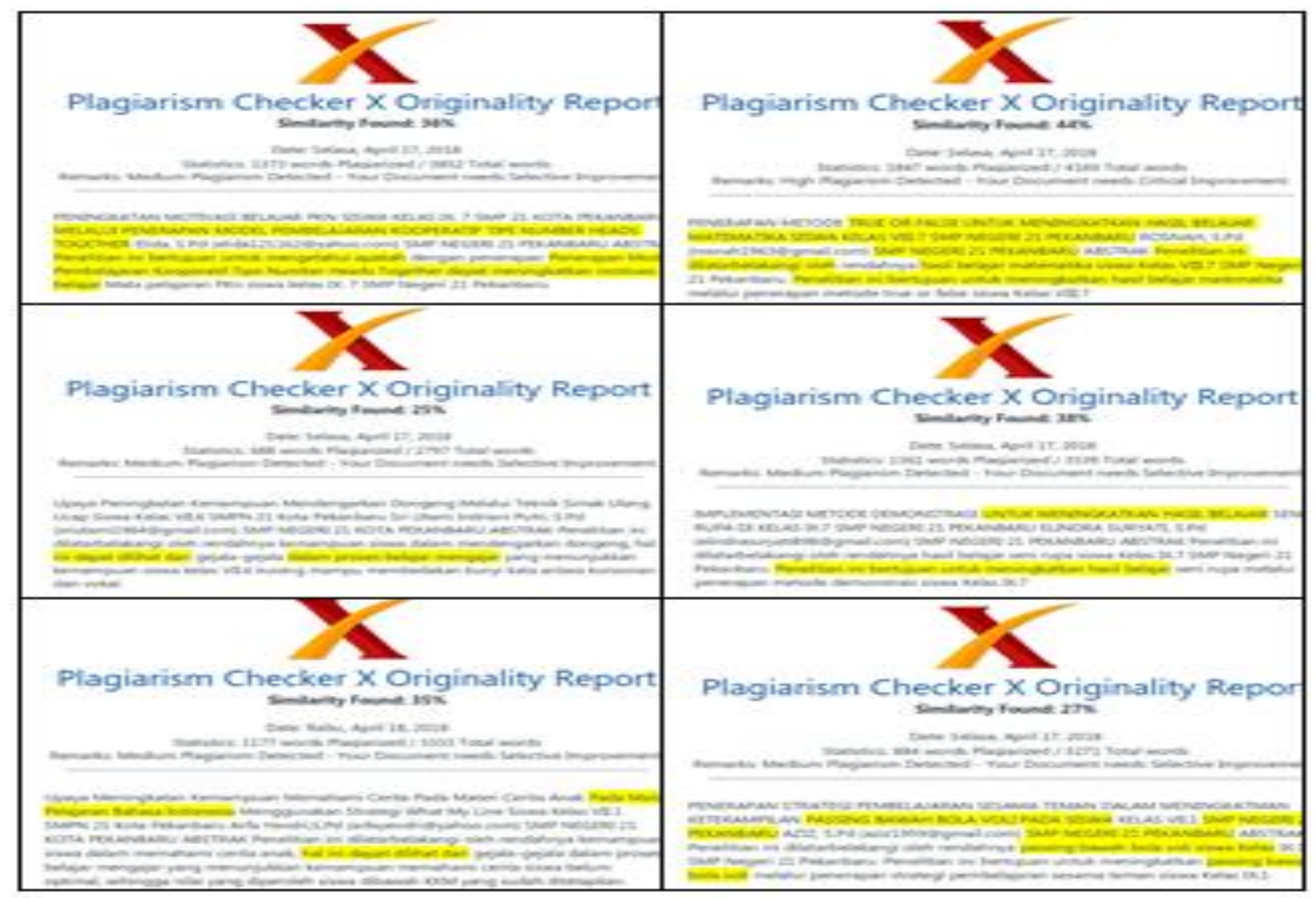

Gambar 2. Hasil Paper di cek dengan Plagiarism Checker 


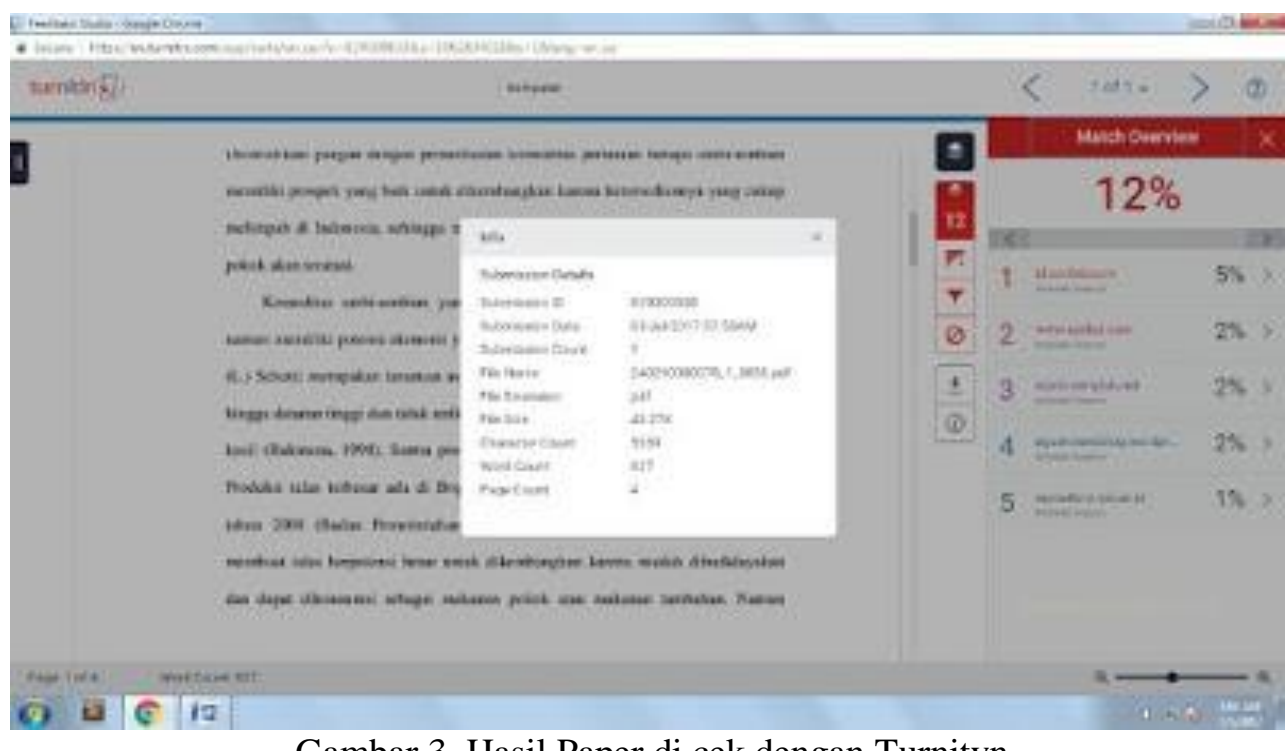

Gambar 3. Hasil Paper di cek dengan Turnityn

\section{KESIMPULAN}

Dari proses pengadaan, pelaksanaan dan monitoring penggunaan aplikasi turnitin, terlihat bahwa aplikasi ini sangat mendukung kualitas dan originalitas artikel jurnal, karya ilmiah mahasiswa dan dosen sebagai insan akademik. Pelaksanaan pelatihannya masih terbatas kepada tim pelaksana pengabdian dan pengelola jurnal yang ada di LPPM serwakilan saja khususnya dari pengelola jurnal fahutan dan fakultas hukum. Hal ini belum terlihat optimal karena belum merangkum segala unit, badan dan lembaga yang ada dilingkungan Universitas Lancang Kuning. Namun sebaliknya untuk mendukung pengadaan aplikasi ini perlu dukungan dari pimpinan Universitas Lancang Kuning.

\section{SARAN}

Setelah masa uji coba turnitin pada tim pelaksana pengabdian selesai di ikuti dengan pembayaran invoice dari rektorat maka agenda selanjutnya disarankan pengoptimalan penggunaan aplikasi turnitis setiap unit, badan dan lembaga agar kualitas Universitas Lancang Kuning semakin unggul sebagaimana yang terangkum dalam visi.

\section{DAFTAR PUSTAKA}

[1] Bahar, Safaruddin, dkk. (Ed). 1996. Integrasi Nasional, Teori, Masalah, dan Strategi. Jakarta: Gramedia.

[2] Cliford, Geertz. 2009. The Interpretation Of Culture. Dalam sebuah jurnal penelitian politik Vol.6, No.1, 2009 Kisruh Pemilu. Jakarta. LIPI Press.

[3] Yandra, A. (2017). PREVENTIF APROACH: BAHAYA BORAK DAN CARA MENGIDENTIFIKASI MAKANAN YANG MENGANDUNG BORAK. Dinamisia: Jurnal Pengabdian Kepada Masyarakat, 1(1, Des), 23-28.

[4] Wahyudin, D. Panduan Publikasi Ilmiah: Perangkat Aplikasi, Standar Penulisan dan Etika Kepengarangan. 